Sains Malaysiana 48(7)(2019): 1491-1502

http://dx.doi.org/10.17576/jsm-2019-4807-18

\title{
Barriers and Enablers to Make Lifestyle Changes among Type 2 Diabetes Patients: A Review
}

(Halangan dan Pemboleh untuk Mengubah Gaya Hidup Pesakit Kencing Manis Jenis 2: Suatu Kajian Semula)

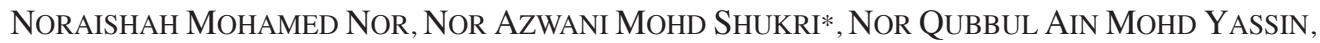
SURIATI SIDEK \& NURANIZA AZAHARI

\begin{abstract}
Type 2 diabetes is a non-communicable disease that affects most people around the world and is generally the result of excessive food intake and physical inactivity. Therefore, the purpose of this review was to identify facilitators and barriers for lifestyle modifications among type 2 diabetes patients. We combined quantitative and qualitative studies for this systematic narrative review. A literary search was carried out using EBSCO, HighWire Press, Medline, PsycInfo, PubMed and Scopus. Narrative review was used to extract results from quantitative studies, while thematic synthesis was used to extract results from qualitative studies. Twenty-three studies were included in this review, with a total of 2287 participants from Western, Arab and Asian populations. The two main themes generated from this review are intrinsic factors and extrinsic factors that can either be facilitators or barriers to implementing lifestyle change. Among the barriers faced by the participants are established food habits, lack of self-efficacy, lack of motivation, lack of social support, inadequate knowledge, low socio-economic status, food culture and poor time management. In contrast, the facilitating factors generated are strong self-efficacy, high motivation, good habits, and sufficient knowledge. In general, patients with diabetes observed more barriers than facilitators to implementing healthy lifestyle changes.
\end{abstract}

Keywords: Barriers; changes; facilitators; lifestyle; type 2 diabetes

ABSTRAK

Diabetes jenis 2 ialah penyakit kronik tidak berjangkit dan semakin ramai populasi dunia yang menghidapinya. Secara umumnya, pengambilan makanan yang berlebihan dan tidak aktif secara fizikal boleh menyumbang kepada peningkatan bilangan pesakit diabetes. Objektifkajian ini adalah untuk menentukan faktor yang menggalakkan dan menghalang pesakit untuk melakukan perubahan gaya hidup daripada segi pemakanan dan aktiviti fizikal. Untuk kajian naratif sistematik ini, kami menggabungkan kajian kuantitatif dan kualitatif. Kami telah melakukan pencarian literatur menggunakan EBSCO, HighWire Press, Medline, PsycInfo, PubMed dan Scopus. Kajian naratiftelah digunakan untuk mengekstrak hasil daripada kajian kuantitatif, sedangkan sintesis tematik digunakan untuk menghasilkan tema daripada kajian kualitatif. Sejumlah dua puluh tiga kajian telah dipilih secara sistematik untuk dianalisis. Jumlah pesakit diabetes yang telibat dalam 23 kajian tersebut adalah seramai 2287 peserta. Dua tema utama yang terbit daripada kajian ini adalah faktor dalaman dan luaran yang boleh menjadi sama ada penggalak atau penghalang untuk membuat perubahan gaya hidup. Antara faktor yang menghalang pesakit diabetes untuk memulakan perubahan gaya hidup adalah tabiat pemakanan, kurang keyakinan diri, kurang motivasi diri, kurang sokongan sosial, kurang pendedahan, status sosioekonomi yang rendah, budaya dan pengurusan masa yang tidak efektif. Faktor yang menggalakkan adalah hampir sama, antaranya adalah keyakinan diri yang tinggi, tabiat pemakanan sihat serta bermotivasi dan pengetahuan yang mencukupi. Secara keseluruhannya, pesakit diabetes mempunyai lebih banyak faktor yang menghalang daripada faktor yang menggalakkan mereka untuk membuat perubahan gaya hidup.

Kata kunci: Diabetes jenis 2; gaya hidup; penggalak; penghalang; perubahan

\section{INTRODUCTION}

Type 2 diabetes mellitus (T2DM) is characterized by insufficiency of insulin production by pancreatic $\beta$-cell, affecting the plasma blood glucose level. This noncommunicable disease is not only influenced by genetic predisposition but also due to other environmental factors, such as unhealthy lifestyle, obesity and the ageing population (Ali 2013; Kolb \& Martin 2017; Tuomilehto et al. 2001). Between 1980 and 2004, the global obesity epidemic due to a sedentary lifestyle and the aging population increased the prevalence of T2DM (Ezzati \& NCD Risk Factor Collaboration 2016). Furthermore, T2DM has been listed as the fifth cause of mortality and the sixth leading cause of physical impairment (Roglic et al. 2005; Seuring et al. 2015).

Research has proven that about $80 \%$ of T2DM can be prevented by implementing lifestyle changes such as eating healthy foods, engaging in physical activity and 
managing weight (Bryant et al. 2009; Kanavos et al. 2012). Lifestyle modifications has shown to be successful in both the prevention and management of T2DM. It is generally believed that controlling food intake with proper intake of medication may control blood glucose level, thus can prevent or delay the complications related to diabetes (Chatterjee et al. 2017; Holma et al. 2008; Miller et al. 2013). A meta-analysis and other research have shown that lifestyle modifications such as healthy eating, performing physical activity and losing weight provide a significant benefit in reducing risk factors related to the cardiovascular disease in diabetic patients, and were able to decrease the diabetic incidence by $50 \%$ in pre-diabetic patients (Ashra et al. 2015; Chen et al. 2015; Klein et al. 2004; Norris et al. 2005). At the moment, lifestyle changes program among diabetic patients with the element of behavioral modification showed a positive outcome among participants (Colagiuri et al. 2010; Li et al. 2008; Lindstrom et al. 2006). However, even with well-structured lifestyle modification programs, success rates were not satisfactory (Chong et al. 2017).

Most of the existing reviews focused mainly on the efficacy of lifestyle interventions but little is known about patients' challenges or barriers in implementing lifestyle changes. This review therefore, sought to evaluate the potential obstacles to lifestyle modification among T2DM patients. In addition, it would also explore strategies for overcoming barriers and making it possible for patients to maintain the change in their new lifestyle.

\section{MATERIALS AND METHODS}

The review method was adopted from Preferred Reporting Items for Systematic review and Meta-Analysis (PRISMA 2009) which is specifically designed for systematic review and meta-analysis (Figure 1). The major sections divided in PRISMA are identification, screening, eligibility and inclusion (Moher et al. 2009). Additionally, this review was registered with Prospero (103099).

\section{SEARCH STRATEGY}

We searched the literature pertaining barriers and facilitators for lifestyle changes among T2DM patients. The search was conducted using several search engines such as EBSCO, HighWire Press, Medline, PsycInfo, PubMed and Scopus. Articles published from January, 1990 until May, 2018 were included.

Search terms were divided into concepts and expanded to create a comprehensive search with synonyms linked to Boolean operators and wildcard. Relevant search terms were used to combine searches such as 'AND', 'OR' and 'NOT' for all databases. The term 'AND' was used to narrow down the search terms, 'OR' to enlarge the search term,
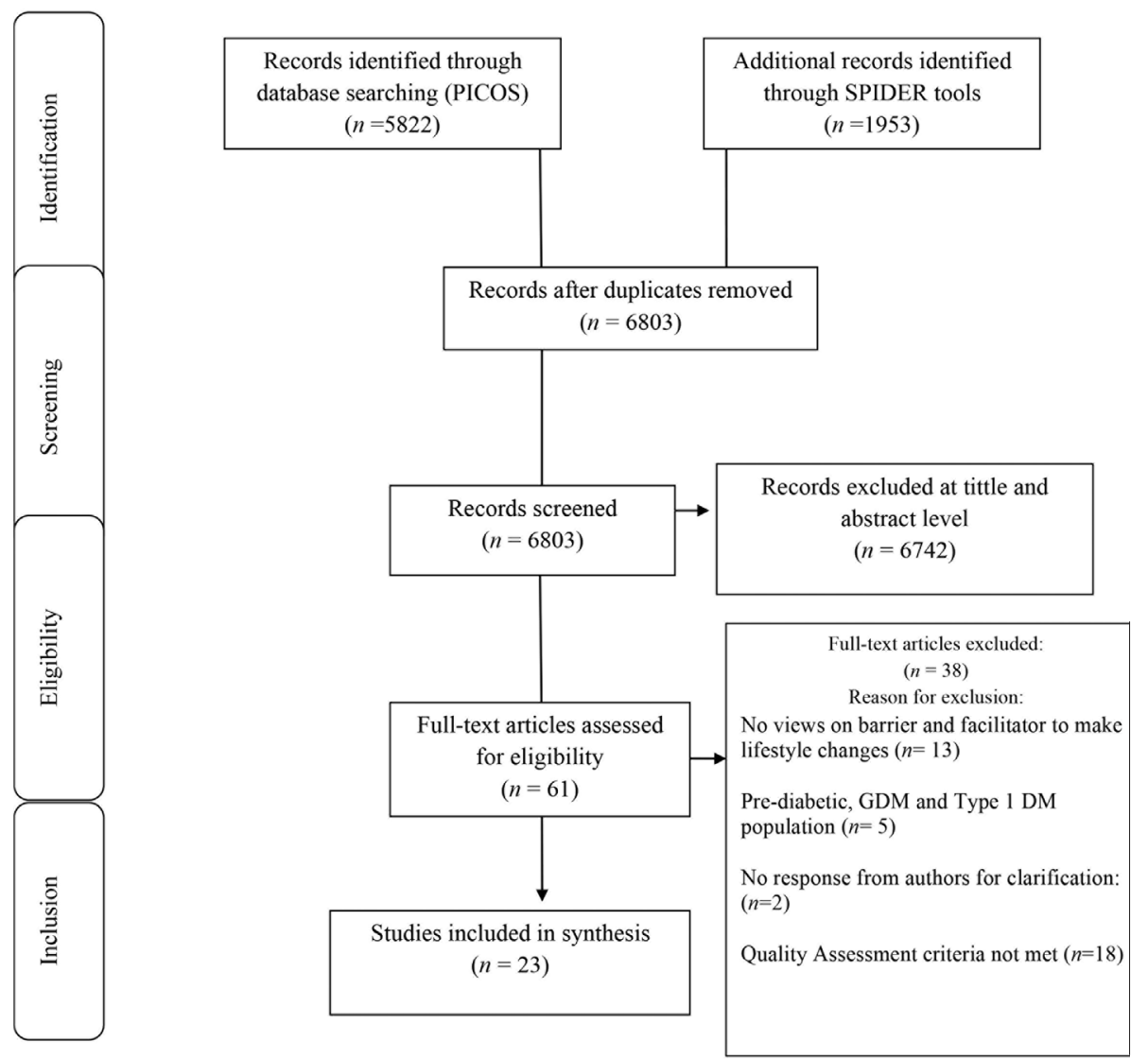

FIGURE 1. Selection process 
and 'NOT' to eliminate the search terms (Learner Support Service (LSS) 2009).

PICOS (Population, Intervention, Comparator, Outcome, and Study design) search strategy tool was used to determine the specific inclusion criteria. On top of PICOS, the search was also done using SPIDER (Sample, Phenomenon of Interest, Design, Evaluation, Research type) search strategy tool to obtain more qualitative study. Table 1 shows the differences between search strategies used based on PICOS and SPIDER tools, and Table 2 lists the example of search terms used in SCOPUS database for each tools.

\section{STUDY SELECTION}

The current review included quantitative, qualitative, and mixed method studies, as long as the study contains the element of barriers to change, facilitators to implement lifestyle changes, or approaches to overcome the barriers. Studies involving pregnant women, children, and patients with type 1 diabetes mellitus, as well as data based on the opinions from health care providers, were excluded. Furthermore, studies that did not meet the quality assessment criteria such as small sample size, use of secondary data and low overall scores were excluded.

TABLE 1. PICOS Vs SPIDER search strategy

\begin{tabular}{ll}
\hline PICOS ELEMENTS & SPIDER \\
\hline Population: & Sample: \\
Inclusion Criteria & Inclusion Criteria \\
Female and male & Female and male \\
Age 18 years old and above & Age 18 years old and above \\
Diabetes mellitus type 2 & Diabetes mellitus type 2 \\
English and Malay paper & English and Malay paper \\
Year 1990-2018 & Year 1990-2018 \\
Exclusion Criteria & Exclusion Criteria \\
Animal studies & Animal studies \\
Pediatrics participant & Pediatrics participant \\
Year <1990 & Year <1990 \\
Other than type 2 DM & Other than type 2 DM \\
Intervention: & Phenomena of Interest: \\
Lifestyle modification & Lifestyle modification \\
Comparator: None & Design: study design \\
Outcomes: & Evaluation: Outcome measures such as attitudes and \\
Blood glucose control & views and so forth \\
Study Designs: & Research Type: \\
Systematic review, random control trial & Qualitative, quantitative, and mixed methods \\
cross sectional study & \\
\hline
\end{tabular}

TABLE 2. Search terms used

\begin{tabular}{|c|c|c|c|}
\hline PICOS tool & Search Terms & SPIDER tool & Search Terms \\
\hline $\mathrm{P}$ & $\begin{array}{l}\text { ('type } 2 \text { diab'* OR 'non-insulin dependent' } \\
\text { OR 'diabetes mellitus') AND NOT (type } 1 \\
\text { AND diab* OR 'insulin dependent diab'* OR } \\
\text { 'gestational diab'*) AND (adult* OR' young } \\
\text { adult' OR 'middle adult' OR 'elderly') }\end{array}$ & $\mathrm{S}$ & $\begin{array}{l}\text { ('type } 2 \text { diab'* OR 'non-insulin dependent' OR } \\
\text { 'diabetes mellitus') AND NOT (type } 1 \text { AND diab* } \\
\text { OR 'insulin dependent diab'* OR 'gestational } \\
\text { diab'*) AND (adult* OR' young adult' OR' middle } \\
\text { adult' OR' elderly') }\end{array}$ \\
\hline $\mathrm{I}$ & $\begin{array}{l}\text { ('lifestyle' OR 'habit'* OR 'behavio?r' OR } \\
\text { 'conduct'*) AND ('barrier*' OR 'obstacle*' } \\
\text { OR 'issue*' OR 'challenge*') AND change* } \\
\text { OR modification* OR transition*) }\end{array}$ & $\mathrm{P} \& \mathrm{I}$ & $\begin{array}{l}\text { ('lifestyle' OR 'habit'* OR 'behavio?r' OR } \\
\text { 'conduct'*) AND ('barrier*' OR 'obstacle*' OR } \\
\text { 'issue*' OR 'challenge*') AND (change* OR } \\
\text { modification* OR transition*) }\end{array}$ \\
\hline $\mathrm{C}$ & None & $\mathrm{D}$ & $\begin{array}{l}\text { ('questionnaire*' OR 'survey*' OR 'interview*' } \\
\text { OR 'focus group*' OR 'case stud*' OR 'observ*') }\end{array}$ \\
\hline $\mathrm{O}$ & $\begin{array}{l}\text { ('diab* AND management*' OR 'diab* AND } \\
\text { control*' OR 'diab* AND prevention*' OR } \\
\text { 'diab* AND treatment* 'OR 'diab* AND } \\
\text { delay') }\end{array}$ & $\mathrm{E}$ & $\begin{array}{l}\text { ('diab* AND management*' OR 'diab* AND } \\
\text { control*' OR 'diab* AND prevention*' OR 'diab* } \\
\text { AND treatment*' OR 'diab* AND delay') }\end{array}$ \\
\hline $\mathrm{S}$ & Not specified & $\mathrm{R}$ & ('quantitative' or 'qualitative' or 'mixed method') \\
\hline
\end{tabular}


By using the PICOS elements, a total of 5822 records were found and 1953 records were found using the SPIDER elements. A total of 6803 records were left after the duplicates were removed. The titles were reviewed from these articles, leaving 1673 articles. Following the abstract review, there were 61 articles left for the full text review. Finally, only 23 studies were included in this review after complete text review and assessing quality (Figure 1).

\section{DATA EXTRACTION AND QUALITY ASSESSMENT}

Records were stored in Mendeley, the free referencing software, for removing duplicates, and for screening of titles and abstracts. An extraction data tool, the Matrix Method developed by Garrard (2017) was used during the data extraction phase (S1). This method meticulously extracted study information, participant's details, and results.

The Critical Appraisal Skills Program (CASP), the Joanna Briggs Institute (JBI) and the National Heart, Lung and Blood Institute (NIH) quality assessment tools were used to evaluate the quality and risk of study biases. JBI and $\mathrm{NIH}$ tools were used to weigh the quality of cross-sectional studies, while CASP was used to weigh randomized control trials (RCT) and qualitative studies. Precise methods for data collection and analysis were applied to the elements obtained from the quality assessment. The reliability and validity of the findings were used to evaluate the strengths and flaws of the included studies.

\section{DATA SYNTHESIS AND ANALYSIS}

The data were recorded in a table that contains all details needed to be compared during data analysis. The table constructed was adapted from Messina et al. (2017). This review was designed to systematically summarize all the gathered articles comprising of both quantitative and qualitative methods.

A mixed systematic review method was used to analyze the quantitative and qualitative studies included in this review (Figure 2). Narrative review was used for the quantitative data, whereas thematic analysis was utilized for qualitative data. This meta-synthesis method will give a broader view of data as it combines both qualitative and quantitative studies. After all the data were tabulated, they were organized according to the types of study, then the analysis process began. As for thematic analysis, Atlas -Ti 8 software (155115406) was used to organize the data and to create the themes and sub-themes.

\section{RESULTS AND DISCUSSION}

\section{PRIMARY STUDY CHARACTERISTICS}

Twenty-three studies with a total of 2287 participants from Western, Arab, and Asian populations were included in this review. The age range for the populations was 18 to 80 years old and there were more female participants $(n=$ 992) compared to males ( $n=671)$ as reported in 13 studies, while another 10 studies reported gender in percentage. Most of the studies were qualitative studies $(n=13)$ and the remaining 10 studies were quantitative studies, resulting in few numbers of total participants ( $\mathrm{N}=2287)$. Methods of data collection used in qualitative studies were indepth, semi-structured, face-to-face interview, focused group discussion, and telephone interview. The methods used for quantitative studies were cross-sectional survey, randomized control trials and case control.

All included studies had clear goals and the selected methods were appropriate for the research questions. All the studies mentioned ethical approval and information on the saturation level was available for qualitative data. Socio-demographic data were also well reported, especially for quantitative studies.

\section{THEMATIC ANALYSIS}

In this review, we identified a few overarching themes for change that are extrinsic and intrinsic factors. The sub-themes emerged from the primary themes to further categorize the sub-themes as either facilitators or barriers to change. Finally, we established the views of the patients to make lifestyle changes in the context of diet and physical activity, and the themes were raised from the included

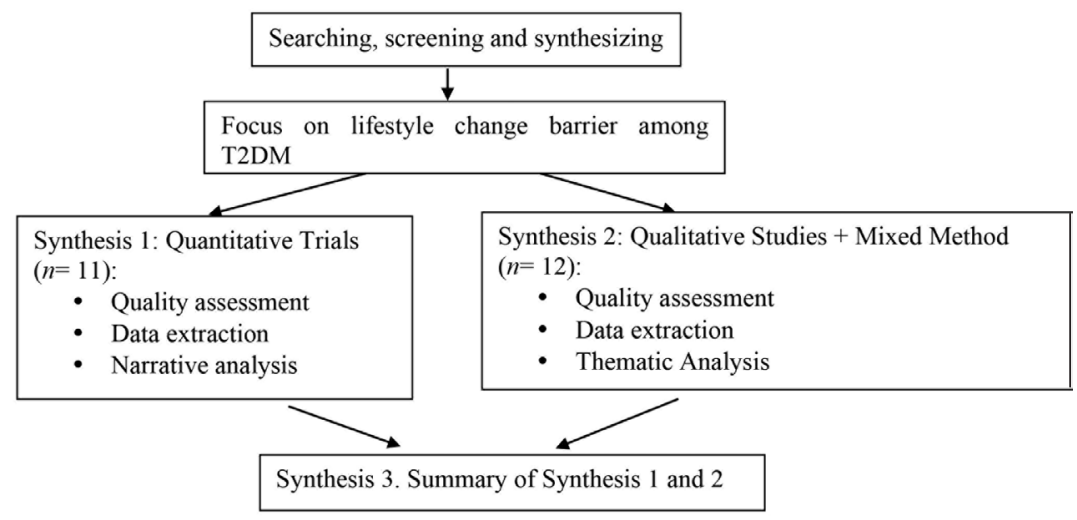

FIGURE 2. Synthesizing technique 
studies. Participants' quotations and statistical results from the articles included were used to further strengthen the results.

\section{BARRIERS TO MAKE LIFESTYLE CHANGES}

Compared to facilitators, there were more barriers to starting or maintaining lifestyle changes. These barriers can be further categorized as intrinsic and extrinsic factors. The barriers identified by intrinsic factors were food habit, self-efficacy, emotional influence, and motivation. The barriers of extrinsic factors explored were social support, knowledge, socio-economic status, socio-cultural factors, environmental factors, and time management.

\section{MAIN THEMES}

Intrinsic barriers to make lifestyle changes The main sub-themes in this category are food habit, self-efficacy, motivation and emotional influence.

Patient's food habit Five qualitative studies mentioned about food habit as a barrier against following a diabetic diet (Brunk et al. 2017; Chary et al. 2012; Ide et al. 2018; Mansyur et al. 2015; Mathew et al. 2012; Sapkota et al. 2017; Savoca \& Miller 2001). Participants clarified that it was very hard to change their eating habit as they had been used to it since they were small (Ide et al. 2018). Apart from the recommended smaller portion size, they also perceived the diabetic diet as rigid and bland, making it very challenging to follow (Brunk et al. 2017; Chary et al. 2012; Ide et al.2018), as stated by one of the participants:

"I think the hardest thing is to get used to the change in taste... "(Patient, Brunk et al. 2017)

Lack of self-efficacy Self-efficacy was also seen as a barrier to change in both physical activity and dietary intake (Akumiah et al. 2017; Booth et al. 2013; Brunk et al. 2017; Byers, et al. 2016; Chary et al. 2012; Ghimire 2017; Ide et al. 2018; Klug et al. 2008; Malpass et al. 2009; Mansyur et al. 2015; Sapkota et al. 2017). Self-efficacy is very crucial in implementing lifestyle changes as it is the willpower to either start or not to start lifestyle changes (Brunk et al. 2017). Most participants felt difficult to control their food intake as they enjoyed food and made no effort to overcome the feeling (Byers et al. 2016; Ide et al. 2018). Other than that, they found it challenging to change well-established lifestyles (Booth et al. 2013; Mathew et al. 2012; Savoca $\&$ Miller 2001). An elderly participant mentioned:

"When you get to your 60's and 70's, it's so hard to change." (FGD 2, Booth et al. 2013).

In a study done by Akumiah et al. (2017), 17.6\% of the participants had low self- efficacy to follow dietary recommendations. Mixed results were reported in terms of self-efficacy and physical activity. As mentioned by Mansyur et al. (2015), barriers to exercise in men and women were strongly associated with self-efficacy $(p<0.001)$ and self-care adherence $(p<0.05)$. However, in a study conducted by Ghimire (2017), self-efficacy $(\mathrm{OR}=0.09)$ was not associated with physical activity engagement. On the other hand, some participants mentioned that diseases such as arthritis, knee pain, asthma, or recent major operation prevented them from exercising (Korkiakangas et al. 2011; Lawton et al. 2006; Malpass et al. 2009).

\section{LACK OF MOTIVATION}

Motivation can be an important factor in changing the lifestyle. Without motivation, most participants were unable to make the necessary changes. Participants felt demotivated to continue with lifestyle changes because they saw no benefit, particularly in terms of changes in blood glucose (Booth et al. 2013; Savoca \& Miller 2001). Despite having a strong family history of T2DM, participants still had no awareness to make lifestyle changes to prevent the disease (Savoca \& Miller 2001).

"Human being is naturally lazy. You can't just force yourself you know, to eat something you know you don't like, I'll eat as normal because I'm taking this metformin medicine." (Male, focus group 5; Booth et al. 2013).

Additionally, emotional factors such as isolation, stress or depression, influenced participants to consume large amounts of junk foods as a source of comfort (Brunk et al. 2017; Savoca \& Miller 2001).

\section{EXTRINSIC BARRIERS TO MAKE LIFESTYLE CHANGES}

Sub-themes generated in this category include social support, knowledge, socioeconomic status, socio-cultural factors, environmental factors and time management.

Lack of social support Social support was perceived either as facilitator or as barrier to make lifestyle changes (Korkiakangas et al. 2011). Several participants felt that people in their surroundings were unable to help them with lifestyle changes (Booth et al. 2013; Ide et al. 2018). This type of barrier is more commonly experienced by women rather than men (Booth et al. 2013; Mansyur et al. 2015). The situation could be worse in rural areas where some people may have negative perception of diabetic patients. Thus, patients tend to keep their diseases for themselves (Ide et al.2018). Lifestyle modification barriers frequently mentioned by participants were lack of spousal support (46.2\%), family members $(73.4 \%)$, and friends (69.3\%) (Akumiah et al. 2017). Additionally, as found in three studies, the barrier to consistently engage in physical activity due to lack of social support was between $10 \%$ and 27\% (Akumiah et al. 2017; Ghimire 2017; Umeh \& Nkombua 2018). Binary logistic regression models were used to identify perceived barriers. About $41 \%$ and $46 \%$ of the participants were noncompliant to diet and exercise advice, respectively; only $35.5 \%$ the participants were 
compliant to both. Perceived social acceptability (OR = 0.14; 95\% CI: 0.03-0.58).

Inadequate knowledge Another significant extrinsic barrier. Adequate knowledge of healthy diets and nutritional needs is very crucial in implementing changes (Sapkota et al. 2017). Although they had been diagnosed with diabetes for some time, some participants still lacked in knowledge regarding diabetic diet (Booth et al. 2013; Brunk et al. 2017). Participants were being fed with too much information at one time that they were unable to recall all of them. This left them clueless about their dietary management, especially in the estimation of portion size, food and the amount they were allowed to consume. (Booth et al. 2013; Byers et al. 2016; Ide et al. 2018). In a study done by Malpass et al. (2009), they found that most participants would use diet and physical activity to compensate for each other. If they follow the dietary recommendation, they would not do exercise, and vice versa. Nonetheless, lack of knowledge should not be seen as a barrier to do physical activity. This is because a study done in Nepal found that among participants who were frequently educated and encouraged by healthcare providers to do physical activity, only $21 \%$ of them really made changes (Malpass et al. 2009).

Socioeconomic status Patients were effected in making consistent dietary changes due to the higher price of healthier foods. Participants agreed that healthy foods cost more, making it more difficult to choose recommended foods, especially fruits and vegetables, unrefined rice or bread than usual foods (Chary et al. 2012; Ide et al. 2018; Marcy et al. 2010). One of the participants in a study mentioned this:

"We are poor. I don't have money, and everything is expensive." (Chary et al. 2012).

Food cultures Food cultures contribute to the development of diabetes-related complication as patients had difficulty changing their daily routine (Sapkota et al. 2017). There were some cultural practices that contradicted with the recommended dietary practice, making it more difficult to modify such as binge drinking, skipping breakfast and attending endless functions (Booth et al. 2013; Chary et al. 2012; Sapkota et al. 2017). Moreover, in Indian culture, mothers-in-law who stay with their son do not have full authority in planning the daily menu for themselves and the family. For example, one elderly participant said she managed to follow the diet after she left her son's house (Chary et al. 2012).

Only one study described the impact of cultural belief on the engagement of physical activity. According to Lawton et al. (2006), most female participants had difficulties following physical activity recommendations due to lack of single-sex facilities. Additionally, women's restriction on leaving the house was also found as a huge hurdle to start physical activity.
Lack of time Daily commitments can lead to meal-skipping or eating any food that was easily available when healthy food choices were not always accessible (Ghimire 2017; Savoca \& Miller 2001). Time management was mentioned more as a barrier to do physical activity than eating healthily. Difficulties in finding time, stress and fatigue after long working hours were also frequently mentioned as barriers to physical activity (Brunk et al. 2017; Ide et al. 2018; Kaltman et al. 2015; Korkiakangas et al. 2011; Lawton et al. 2006). This is further supported by a study by Umeh and Nkombua (2018), they found that the barriers to engage in exercise include not having the time (43.9\%), not having companions (19.4\%), stress $(16.3 \%)$, and bad climate $(10.2 \%)$. In addition, rainy weather, seasonal issues such as a long winter, safety issues, lack of facilities and proper place to do physical activity were also mentioned as environmental barriers to achieving their physical activity recommendation (Akumiah et al. 2017; Booth et al. 2013; Ghimire 2017; Korkiakangas et al. 2011; Lawton et al. 2006).

\section{INTRINSIC FACTORS AS FACILITATORS TO LIFESTYLE CHANGES}

Sub-themes extracted for this category are similar to the extrinsic factors that are self-efficacy, motivation and habit.

Self-efficacy A decisive factor in starting lifestyle changes for a patient. Most participants realized that only they, themselves can manage their diabetes. Strong self-efficacy has enabled them to make the necessary lifestyle changes (Brunk et al. 2017; Rise et al. 2013). Additionally, strong self-efficacy is a key to success in lifestyle changes. For example, in order to avoid eating unhealthy foods, most participants refrained themselves from buying the foods in the first place or bringing lunch box to the office (Byers et al. 2016; Savoca \& Miller 2001). In a study done by Klug et al. (2008), The level of self-efficacy in eating healthy food and doing physical activity showed improvement after obtaining the necessary knowledge at which the confidence rate of the participants increased from 6.6 to 7.7. Significantly higher self-efficacy $(p=0.003)$ was associated with better female self-care adherence (Mansyur et al. 2015).

Motivation It is necessary to start changing lifestyle. For instance, due to fear of needles (insulin injection) and desire to delay diabetic complications, participants were motivated to make lifestyle changes (Brunk et al. 2017; Byers et al. 2016; Lawton et al. 2006). Participants were also motivated to sustain diet and physical activity when they felt the benefits of experiencing weight loss, became more energetic and experienced slow progression of complications (Booth et al. 2013; Korkiakangas et al. 2011; Malpass et al. 2009; Rise et al. 2013). Moreover, some highly motivated participants mentioned that lifestyle changes such as healthy eating, blood sugar 
monitoring and exercise were easier to maintain when they became habits (Rise et al. 2013).

\section{EXTRINSIC FACTOR AS FACILITATOR TO LIFESTYLE CHANGES}

Sub-themes developed in this category include social support and knowledge.

Social support is an important facilitating factor for patients to make changes. Family members helped prepare or encourage healthy eating by changing the eating pattern of the whole family. Exercising together also resulted in a better lifestyle, better blood glucose and adherence to medication (Booth et al. 2013; Byers et al. 2016; Chary et al. 2012; Ide et al. 2018; Kaltman et al. 2015; Savoca \& Miller 2001). Mathew et al. (2012) found that wives are a key support for men. On the other hand, women were reported for the mixed support from daughters, sisters, and friends.

"Family support's been great, you know wife and daughter - both for different reasons.” (Male, focus group 4, Booth et al. 2013).

Participants in a qualitative study mentioned support group and help from friends in sharing ways to manage and cope with their diabetes (Byers et al. 2016). This was supported by a quantitative study showing significant reduction in $\mathrm{HbA} 1 \mathrm{C}(p=0.05)$, improvement in self-management, self-efficacy, and quality of life scores $(p<0.001)$ in peer supported group (Peimani et al. 2017). Likewise, health care providers (HP) who guided participants in setting goals, providing them with adequate knowledge and reviewing their health were seen as motivators for change (Booth et al. 2013; Byers et al. 2016). In terms of dietary management, if patients lived with nuclear families, it was easier to get encouragement for healthy eating. Living with extended families could place a burden on food preparation (Sapkota et al. 2017).

Adequate knowledge is essential for the participants. It creates awareness for them to make lifestyle changes - to eat healthily, engage in physical activity, and perform blood glucose self-monitoring at home (Brunk et al. 2017; Malpass et al. 2009; Rise et al. 2013). In addition, a significant improvement was observed among participants in healthy eating and physical activity by attending a 4-month educational intervention. The average healthy eating frequency increased from 3.9 to 4.1 days $(p=0.009)$, while physical activity increased from 2.9 to 3.5 days $(p=0.02)$ (Klug et al. 2008). In addition, coping planning (to prevent relapse) $(p<0.001)$ and self-efficacy $(p<0.05)$ have been increased at all levels of educational groups without being confounded by the different levels of socioeconomic status (Hankonen et al. 2009).

\section{DISCUSSION}

In this systematic review, several barriers and facilitators were identified among T2DM patients to make lifestyle changes in food intake and physical activity. The results indicated that participants reported more barriers than facilitators in making changes to the overall lifestyle. Table 3 summarizes the overall findings together with recommendations for each incipient theme. This review found that the main barrier to changing current lifestyle among patients was due to their own desire or ability to do so. In addition, adequate knowledge, social support and high motivation can make it easier for them to change consistently over the long term. A thematic map (Figure 3 ) was developed to summarize the emerging themes and sub-themes from the 23 papers. Lifestyle, which includes unhealthy food intake and sedentary lifestyle, is strongly associated with the development of T2DM. High intake of carbohydrates such as rice and sugar-sweetened beverages in combination with physical inactivity increases the risk of T2DM advancement (ADA 2003; Malik et al. 2010; Sun et al. 2010). The Diabetes Prevention Program (DPP) study, indicated that intervention with metformin and overall lifestyle changes successfully delayed diabetes progress, but lifestyle intervention was more powerful than metformin, as lifestyle intervention reduced incidence by $58 \%$ while metformin by $31 \%$ (Diabetes Prevention Program Research Group 2011; Knowler et al. 2002; Ratner 2006). In addition, the Finnish Diabetes Prevention Study, adults at high risk for T2DM benefited more from intensive lifestyle changes program including diet and physical activity compared to control group (Crandall et al. 2006; Lindström et al. 2008). The major finding from the Finnish Study was non-pharmacological lifestyle intervention could prevent or delay the onset of getting T2DM among pre-diabetic patients (Lindström et al. 2003). Therefore, lifestyle changes are perceived as highly important for pre-diabetic and T2DM patients.

This review evaluated the most up-to-date literature on barriers and facilitators to make lifestyle changes among diabetic patients. We also pointed out that intrinsic factors were a greater concern compared to extrinsic factors. The evidence showed that the self-efficacy and motivation of the patient, together with adequate knowledge, can significantly forecast behavioural changes. Motivation and self-efficacy (self-confidence) were important to form an intention to change. With intention and proper education, an individual can achieve his or her specific goals with the belief that they will maintain the changes (Dixon 2008; Lemacks et al. 2013; Riekert et al. 2014).

Despite this, extrinsic factors also play a role in behavioural changes. The intrinsic factors can be intensified by factors such as social support, financial capacity, cultural issue and time. Low economic status was found to be positively related to low adherence to diet, physical activity and medical recommendations (Jadawala et al. 2017; Khan et al. 2012). In addition, social 
TABLE 3. Summary of findings and recommendations

Main themes
\begin{tabular}{l} 
Emerging sub - themes \\
\hline Intrinsic barriers
\end{tabular}
Low self- efficacy to start changes
No motivation to make changes
Lack of support from surrounding people
Extrinsic barriers
Inadequate knowledge to implement proper
changes

Inadequate knowledge to implement proper Patients should be provided with proper education regarding diabetic diet and physical activity at the early stage of diagnosis to prevent them from practising wrong diet

Skill-building activities, time management skills, and problem-solving methods, are needed in education session

Socioeconomic as a barrier to eat healthily

Sociocultural was barrier in some nation
Educators should focus on portion size rather than suggesting different types of healthy choice's foods

Educators should be culturally aware and sensitive, to be able to tailor the recommendation with patient's preference

For physical activity, the authorities should build more facilities indoor with gender different facilities (Byers et al. 2016)

Limited time to do physical activity and eat Educators should encourage patient to do healthy food basic physical activity and plan ahead for the meal

Environmental factors that affecting lifestyle changes

Government should create more conducive and supportive environment to promote physical activity and dietary education in the community (Umeh \& Nkombua 2018)

Intrinsic facilitators

High self-efficacy to engaged in lifestyle changes

High motivation is always needed to maintain the changes

Lifestyle change was adopted as a daily habits

Extrinsic facilitators

Social support especially family support is very important to make lifestyle changes

Future research may explore this factor by in-depth interview to find out the ways to increase self-efficacy and motivation among NCD patients

Patients should be reminded regularly, through follow-up call to maintain the changes for long term

Family members should be educated on how to help patient to make changes, for example by doing physical activity together and eating healthy food daily

Adequate knowledge is crucial to make and Patients should be updated with knowledge maintain changes regularly, as knowledge is interrelated with self-efficacy 


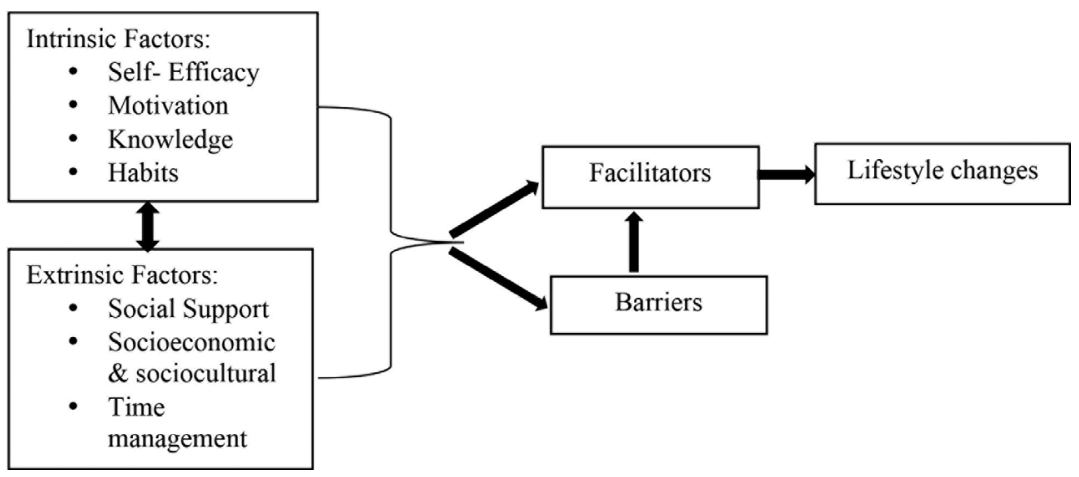

FIGURE 3. Thematic framework for barrier and facilitator to make lifestyle changes among DM

support, especially family support, was found to increase adherence to diet and exercise compared to those without support (Engbers et al. 2006; Jadawala et al. 2017; Laranjo et al. 2015). Culture and time, on the other hand, were seen as barriers rather than facilitators. Research conducted by Jadawala et al. (2017) and Khan et al. (2012) found that busy schedules were the main factor in non-adherence to physical activity recommendation, whereas the effect of culture was mostly seen among women in rural Asian and Arab countries (Al-Kaabi et al. 2009; Lawton et al. 2006; Medagama \& Galgomuwa 2018).

Each of the factors could serve as a barrier or facilitator for changes to diabetic patients' lifestyles. From this review, most patients perceived most of the factors as barriers rather than facilitators, leaving them with excuses to make changes. As a result, healthcare professionals should identify all the factors that enable or impede a patient to adopt lifestyle changes by providing ongoing education on the benefits of lifestyle changes, as well as support and frequent follow-up to enhance their self-efficacy.

\section{CONCLUSION}

This review adds to the existing literature on facilitators and barriers for engaging in lifestyle changes among diabetic patients by systematically finding the factors that hinder patients from making changes. This result can be used by healthcare professionals to provide an intervention with comprehensive advice and apposite technique. Some patients are not aware of the importance of changing the lifestyle in avoiding diabetic complications. Likewise, it will be very helpful if every newly diagnosed diabetic patient is referred to either a dietitian or diabetic educator to enhance patient's knowledge of diabetes and the appropriate way to make lifestyle changes. Due to a large number of patients every day, the workload of medical professionals seems to be heavy. Early education for diabetic patients can therefore reduce the burden of health care providers in dealing with other diabetes-related complications.

Most of the barriers and facilitators found were homogeneous across countries, including among the indigenous populations. These include knowledge, selfefficacy, habits, motivation, lack of time, and social support and only few Asian and Arab women found that sociocultural practice can be their barrier to change. This finding therefore suggested that lifestyle interventions are interchangeable between countries.

\section{STRENGTH, LIMITATIONS AND FUTURE RESEARCH}

Previous reviews (Joseph-Williams et al. 2014; Messina et al. 2017; Sohal et al. 2015) mostly discussed diabetes prevention as a whole without focusing on the patients' barriers and lifestyle change facilitators. Therefore, this review focuses on facilitating and hindering factors for diabetic patients to make changes, subsequently providing recommendations for overcoming barriers. Future work should focus on assessing the efficiency of early diabetic education in the prevention or delay of diabetes complications since this review found that some patients did not know about diabetes diet from the early stage. The findings also suggested that patients were unwilling to change due to lack of self-efficacy, therefore, initiatives to explore self-efficacy may help to increase adherence to lifestyle changes.

This review has its limitations. Firstly, only published journal articles on free or subscribed databases were included, thus some common databases such as CINAHL and Web of Sciences were not included. Moreover, the variables among the quantitative studies were inconsistent, disabling a meta-analysis.

\section{ACKNOWLEDGEMENTS}

This research has been financially supported by Research Initiative Grant Scheme, International Islamic University Malaysia (RIGS17-149-0724).

\section{REFERENCES}

ADA. 2003. Physical activity/exercise and diabetes mellitus. Diabetes Care 26(1): 73-77.

Akumiah, P.O., Samuel, O.A., Azumah Nayembil, D., Ofosu Agyapong, G. \& Fataw, P. 2017. Barriers to adherence to diet and exercise recommendation amongst Type 2 diabetes mellitus patients. Journal of Health, Medicine and Nursing 39(0): 48-53. 
Al-Kaabi, J., Al-Maskari, F., Saadi, H., Afandi, B., Parkar, H. \& Nagelkerke, N. 2009. Physical activity and reported barriers to activity among Type 2 diabetic patients in the United Arab Emirates. Review of Diabetic Studies 6(4): 271-278.

Ali, O. 2013. Genetics of Type 2 diabetes. World Journal of Diabetes 4(4): 114-123.

Ashra, N.B., Spong, R., Carter, P., Davies, M.J., Dunkley, A., Gillies, C., Khunti, K., Yates, T. \& Youssef, D. 2015. A systematic review and meta-analysis assessing the effectiveness of pragmatic lifestyle interventions for the prevention of Type 2 diabetes mellitus in routine practice about public health england. Public Health England. Wellington House.

Booth, A.O., Lowis, C., Dean, M., Hunter, S.J. \& McKinley, M.C. 2013. Diet and physical activity in the self-management of Type 2 diabetes: Barriers and facilitators identified by patients and health professionals. Primary Health Care Research \& Development 14(3): 293-306.

Brunk, D.R., Taylor, A.G., Clark, M.L., Williams, I.C. \& Cox, D.J. 2017. A culturally appropriate self-management program for hispanic adults with Type 2 diabetes and low health literacy skills. Journal of Transcultural Nursing 28(2): 187-194.

Bryant, T., Leaver, C. \& Dunn, J. 2009. Unmet healthcare need, gender, and health inequalities in Canada. Health Policy 91(1): 24-32.

Byers, D., Garth, K., Manley, D. \& Chlebowy, D.O. 2016. Facilitators and barriers to self-management of Type 2 diabetes among urban African American adults. Journal of Health Disparities Research and Practice 9(1): 164-174.

Chary, A., Greiner, M., Bowers, C. \& Rohloff, P. 2012. Determining adult Type 2 diabetes-related health care needs in an indigenous population from rural Guatemala: A mixed-methods preliminary study. BMC Health Services Research 12: 476.

Chatterjee, S., Khunti, K. \& Davies, M.J. 2017. Type 2 diabetes. The Lancet 389(10085): 2239-2251.

Chen, L., Pei, J.H., Kuang, J., Chen, H.M., Chen, Z., Wen Li, Z. \& Yang, H.Z. 2015. Effect of lifestyle intervention in patients with Type 2 diabetes: A meta-analysis. Metabolism: Clinical and Experimental 64(2): 338-347.

Chong, S., Ding, D., Byun, R., Comino, E., Bauman, A. \& Jalaludin, B. 2017. Lifestyle changes after a diagnosis of Type 2 diabetes. Diabetes Spectrum 30(1): 43-50.

Colagiuri, S., Vita, P., Cardona-Morrell, M., Singh, M.F., Farrell, L., Milat, A., Haas, M. \& Bauman, A. 2010. The Sydney diabetes prevention program: A community-based translational study. BMC Public Health 10: 328.

Crandall, J., Schade, D., Ma, Y., Fujimoto, W.Y., Barrett-Connor, E., Flower, S., Dagogo-Jack, S. \& Andres, R. 2006. The influence of age on the effects of lifestyle modification and metformin in prevention of diabetes. J. Gerontol. A Biol. Sci. Med. Sci. 61(10): 1075-1081.

Diabetes Prevention Program Research Group. 2011. 10-year follow-up of diabetes incidence and weight loss in the Diabetes Prevention Program Outcomes Study. NIH Public Access 374(9702): 1677-1686.

Dixon, A. 2008. Motivation and confidence: What does it take to change behaviour? The Kings Fund. https://doi.org/10.2190/ G8QW-TT09-67PL-QTNC.

Engbers, L.H., Mireille, N.M., Van Poppel, A., Paw, M.C. \& Van Mechelen, W. 2006. The effects of a controlled worksite environmental intervention on determinants of dietary behavior and self-reported fruit, vegetable and fat intake. BMC Public Health 6: 1-10.

Ezzati, M. \& NCD Risk Factor Collaboration. 2016. Worldwide trends in diabetes since 1980: A pooled analysis of 751 population-based studies with 4.4 million participants. Lancet (London, England) 387(10027): 1513-1530.

Garrard, J. 2017. Health Sciences Literature Review Made Easy: The Matrix Method. Fifth Edition. Burlington, Massachusetts: Jones \& Bartlett Learning.

Ghimire, S. 2017. Barriers to diet and exercise among Nepalese Type 2 diabetic patients. International Scholarly Research Notices 2017: 1273084.

Hankonen, N., Absetz, P., Haukkala, A. \& Uutela, A. 2009. Socioeconomic status and psychosocial mechanisms of lifestyle change in a Type 2 diabetes prevention trial. Annals of Behavioral Medicine 38(2): 160-165.

Holman, R.R., Paul, S.K., Bethel, M.A., Matthews, A.A. \& Neil, H.A.W. 2008. 10-year follow-up of intensive glucose control in Type 2 diabetes. New England Journal of Medicine 359(15): 1577-1589.

Ide, N., LoGerfo, J.P. \& Karmacharya, B. 2018. Barriers and facilitators of diabetes services in Nepal: A qualitative evaluation. Health Policy and Planning 33(4): 474-482.

Tuomilehto, J., Lindström, J., Eriksson, J.G., Valle, T.T., Hämäläinen, H., Ilanne-Parikka, P., Keinänen-Kiukaanniemi, S., Laakso, M., Louheranta, A., Rastas, M., Salminen, V., Uusitupa, M. \& Finnish Diabetes Prevention Study Group. 2001. Prevention of Type 2 diabetes mellitus by changes in lifestyle among subjects with impaired glucose tolerance. The New England Journal of Medicine 344(18): 1343-1350.

Jadawala, H.D., Pawar, A.B., Patel, P.B., Patel, K.G., Patel, S.B. \& Bansal, R.K. 2017. Factors associated with non adherence to diet and physical activity among diabetes patients: A cross sectional study. Ntl. J. Community Med. 8(2): 68-73.

Joseph-Williams, N., Elwyn, G. \& Edwards, A. 2014. Knowledge is not power for patients: A systematic review and thematic synthesis of patient-reported barriers and facilitators to shared decision making. Patient Education and Counseling 94(3): 291-309.

Kaltman, S., Talisman, N., Serrano, A., Cabassa, L.J., Magee, M.F., Pulgar-Vidal, O., Peraza, D. \& Cohen, N.R. 2015. Type 2 diabetes and depression: Patient, family member, and primary care provider perspectives on the development of an integrated self-management intervention. The Diabetes Educator 41(6): 763-772.

Kanavos, P., Van Den Aardweg, S. \& Schurer, W. 2012. Diabetes expenditure, burden of disease and management in $5 \mathrm{EU}$ countries. LSE Health 1: 1-113.

Khan, A., Al-Abdul Lateef, Z., Al Aithan, M., Bu-Khamseen, M., Al Ibrahim, I. \& Khan, S. 2012. Factors contributing to noncompliance among diabetics attending primary health centers in the Al Hasa district of Saudi Arabia. Journal of Family and Community Medicine 19(1): 26-32.

Klein, S., Sheard, N.F., Pi-Sunyer, X., Daly, A., Wylie-Rosett, J., Kulkarni, K. \& Clark, N.G. 2004. Weight management through lifestyle modification for the prevention and management of type 2 diabetes: Rationale and strategies. Diabetes Care 27(8): 2067-2073.

Klug, C., Toobert, D.J. \& Fogerty, M. 2008. Healthy changes ${ }^{\mathrm{TM}}$ for living with diabetes: An evidence-based community diabetes self-management program cindy. HHS Public Access 6(34): 1053-1061.

Knowler, W.C., Barett-Connor, E., Fowler, S.E., Hamman, R.F., Lachin, J.M., Walker, E.A. \& Nathan, D.M. 2002. Reduction in the incidence of Type 2 diabetes with lifestyle intervention or metformin. New England Journal of Medicine 346(6): 393-403. 
Kolb, H. \& Martin, S. 2017. Environmental/lifestyle factors in the pathogenesis and prevention of Type 2 diabetes. $B M C$ Medicine 15(1): 1-11.

Korkiakangas, E.E., Alahuhta, M.A., Husman, P.M., KeinänenKiukaanniemi, S., Taanila, A.M. \& Laitinen, J.H. 2011. Motivators and barriers to exercise among adults with a high risk of Type 2 diabetes - A qualitative study. Scandinavian Journal of Caring Sciences 25(1): 62-69.

Laranjo, L., Neves, A.L., Costa, A., Ribeiro, R.T., Couto, L. \& Sá, A.B. 2015. Facilitators, barriers and expectations in the self-management of Type 2 diabetes - A qualitative study from Portugal. European Journal of General Practice 21(2): 103-110.

Lawton, J., Ahmad, N., Hanna, L., Douglas, M. \& Hallowell, N. 2006. I can't do any serious exercise: Barriers to physical activity amongst people of Pakistani and Indian origin with Type 2 diabetes. Health Education Research 21(1): 43-54.

Lemacks, J., Wells, B.A., Ilich, J.Z. \& Ralston, P.A. 2013. Interventions for improving nutrition and physical activity behaviors in adult African American populations: A systematic review, January 2000 through December 2011. Preventing Chronic Disease 10(1): 120256.

Li, G., Zhang, P., Wang, J., Gregg, E.W., Yang, W., Gong, Q., Li, H., Jiang, Y., An, Y., Shuai, Y., Zhang, B., Zhang, J., Thompson, T.J., Gerzoff, R.B., Roglic, G., Hu, Y. \& Bennett, P.H. 2008. The long-term effect of lifestyle interventions to prevent diabetes in the China Da Qing diabetes prevention study: A 20-year follow-up study. The Lancet 371(9626): 1783-1789.

Lindström, J., Peltonen, M., Eriksson, J.G., Hamalainen, H., Ilanne-Parikka, P., Keinanen-Kiukaanniemi, S., Uusitupa, M. \& Tuomilehto, J. 2008. Determinants for the effectiveness of lifestyle intervention in the Finnish Diabetes Prevention Study. Diabetes Care 31(5): 857-862.

Lindstrom, J., Ilanne-Parikka, P., Peltonen, M., Aunola, S., Eriksson, J.G., Hemio, K., Hamalainen, H., Härkönen, P., Keinänen-Kiukaanniemi, S., Laakso, M., Louheranta, A., Mannelin, M., Paturi, M., Sundvall, J., Valle, T.T., Uusitupa, M., Tuomilehto, J. \& Finnish Diabetes Prevention Study Group. 2006. Sustained reduction in the incidence of type 2 diabetes by lifestyle intervention: Follow-up of the Finnish Diabetes Prevention Study. The Lancet 368(9548): 1673-1679.

Lindström, J., Louheranta, A., Mannelin, M., Rastas, M., Salminen, V., Eriksson, J., Uusitupa, M. \& Tuomilehto, J. 2003. The Finnish Diabetes Prevention Study (DPS). Diabetes Care 26(12): 3230-3236.

Malik, V.S., Popkin, B.M., Bray, G.A., Despres, J.P., Willett, W.C. \& Hu, F.B. 2010. Sugar sweetened beverages and risk of metabolic syndrome and Type 2 diabetes: A meta-analysis. Diabetes Care 33(11): 2477-2483.

Malpass,A.,Andrews, R. \& Turner, K.M. 2009. Patients with Type 2 diabetes experiences of making multiple lifestyle changes: A qualitative study. Patient Education and Counseling 74(2): 258-263.

Mansyur, C.L., Rustveld, L.O., Nash, S.G. \& Jibaja-Weiss, M.L. 2015. Social factors and barriers to self-care adherence in hispanic men and women with diabetes. Patient Education and Counseling 98(6): 805-810.

Marcy, T.R., Britton, M.L. \& Harrison, D. 2010. Identification of barriers to appropriate dietary behavior in low-income patients with Type 2 diabetes mellitus. Diabetes Therapy 2(1): 9-19.
Mathew, R., Gucciardi, E., Melo, M.D. \& Barata, P. 2012. Selfmanagement experiences among men and women with Type 2 diabetes mellitus: A qualitative analysis. BioMed Central Family Practice 13: 122.

Medagama, A. \& Galgomuwa, M. 2018. Lack of infrastructure, social and cultural factors limit physical activity among patients with Type 2 diabetes in Rural Sri Lanka, a qualitative study. PLOS ONE 13(2): 1-8.

Messina, J., Campbell, S., Morris, R., Eyles, E. \& Sanders, C. 2017. A narrative systematic review of factors affecting diabetes prevention in primary care settings. PLOS ONE 12(5): 1-20.

Miller, K.M., Beck, R.W., Bergenstal, R.M., Goland, R.S., Haller, M.J., McGill, J.B., Rodriguez, H., Simmons, J.H. \& Hirsch, B . 2013. Evidence of a strong association between frequency of self-monitoringof blood glucose and hemoglobin A1c levels in T1D exchange clinic registry participants. Diabetes Care 36(7): 2009-2014

Moher, D., Liberati,A., Tetzlaff,J. \& Altman, D.G. 2009.Preferred reporting items for systematic reviews and meta-analyses: The PRISMA statement. Journal of Clinical Epidemiology 62(10): 1006-1012. https://doi.org/10.1016/j.jclinepi.2009.06.005.

Norris, S.L., Zhang, X., Avenell, A., Gregg, E., Bowman, B., Schmid, C.H. \& Lau, J. 2005. Long-term effectiveness of weight-loss interventions in adults with pre-diabetes: A review. American Journal of Preventive Medicine 28(1): 126-139.

Peimani, M., Monjazebi, F., Ghodssi-Ghassemabadi, R. \& NasliEsfahani, E. 2017. A peer support intervention in improving glycemic control in patients with Type 2 diabetes. Patient Education and Counseling 101(3): 460-466.

Ratner, R.E. 2006. An update on the diabetes prevention program. Endocr. Pract. 12(2): 105-109.

Riekert, K.A., Ockene, J.K. \& Pbert, L. 2014. The Handbook of Health Behavior Change Models. New York: Springer.

Rise, M.B., Pellerud, A., Rygg, L. \& Steinsbekk,A. 2013. Making and maintaining lifestyle changes after participating in group based Type 2 diabetes self-management educations: A qualitative study. PLOS ONE 8(5): 1-8.

Roglic, G., Unwin, N., Bennett, P.H., Mathers, C., Tuomilehto, J., Nag, S., Connolly, V. \& King, H. 2005. The burden of mortality attributable to diabetes: Realistic estimates for the year 2000. Diabetes Care 28(9): 2130-2135.

Sapkota, S., Brien, J.A.E., Gwynn, J., Flood, V. \& Aslani, P. 2017. Perceived impact of Nepalese food and food culture in diabetes. Appetite 113: 376-386.

Savoca, M. \& Miller, C. 2001. Food selection and eating patterns: Themes found among people with Type 2 diabetes mellitus. Journal of Nutrition Education 33(4): 224-233.

Seuring, T., Archangelidi, O. \& Suhrcke, M. 2015. The economic costs of Type 2 diabetes: A global systematic review. PharmacoEconomics 33(8): 811-831.

Shanti, K. \& Aro, A.R. 2018. Barriers and facilitators to physical activity among urban residents with diabetes in Nepal. PLOS ONE 13(6): 1-21.

Sohal, T., Sohal,P., King-Shier, K.M. \& Khan, N.A. 2015. Barriers and facilitators for Type 2 diabetes management in South Asians: A systematic review. PLoS ONE 10(9): 1-15.

Sun, Q., Spiegelman, D., van Dam, R.M., Holmes, M.D., Malik, V.S., Willett, W.C. \& Hu, F.B. 2010. White rice, brown rice, and risk of Type 2 diabetes in US men and women. Archives of Internal Medicine 170(11): 961-969. 
Umeh, A.E. \& Nkombua, L. 2018. A study of the knowledge and practice of lifestyle modification in patients with Type 2 diabetes mellitus in middelburg sub-district of Mpumalanga. South African Family Practice 60(1): 26-30.

Kulliyyah of Allied Health Sciences

Department of Nutrition Sciences

International Islamic University Malaysia, Kuantan Campus

25200 Kuantan, Pahang Darul Makmur

Malaysia
*Corresponding author; email: norazwani@iium.edu.my

Received: 11 February 2019

Accepted: 10 April 2019 